\title{
A CULTURA-MUNDO E A ÁREA DE EDUCAÇÃO FÍSICA/CIÊNCIAS DO ESPORTE
}

\author{
MS. ALAN CAMARGO SILVA \\ Programa de Pós-graduação em Saúde Coletiva, Instituto de Estudos \\ em Saúde Coletiva, Universidade Federal do Rio de Janeiro \\ (Rio de Janeiro - Rio de Janeiro - Brasil) \\ E-mail: alan10@zipmail.com.br
}

LIPOVETSKY, G.; SERROY, J. A cultura-mundo: resposta a uma sociedade desorientada. Trad. Maria L. Machado. São Paulo: Companhia das Letras, 20 I I 207 p.

Filiados à Universidade de Grenoble (França), com rigor e profundidade teórica, os autores Gilles Lipovetsky (filósofo) e Jean Serroy (especialista em literatura do século XVII e cinema contemporâneo) buscam refletir criticamente sobre a sociedade contemporânea, de modo denso e instigante. Renomado internacionalmente, Lipovetsky (2009) se tornou bastante conhecido por analisar a sociedade moderna por meio da moda e do consumo.

A questão norteadora "Qual é a cultura que caracteriza o mundo de hoje?" orienta os autores ao longo do livro "A cultura-mundo: resposta a uma sociedade desorientada". Ao analisarem a vida contemporânea, a leitura da obra de Gilles Lipovetsky e de Jean Serroy leva a questionar como a área de Educação Física/ Ciências do Esporte vem sendo constituída a partir das mudanças na sociedade em geral. O livro baseia-se, em especial, nas mudanças culturais vinculadas essencialmente às significativas alterações econômicas. Entende-se que por tratar o sujeito a partir dos rearranjos das relações sociais e da própria identidade, a leitura desse livro na área de Educação Física/ Ciências do Esporte se justifica.

Na introdução do livro, os autores esclarecem que a cultura-mundo seria uma cultura globalizada do mundo hipermoderno regida pelas lógicas do individualismo e do consumismo, típicas do sistema capitalista. Nesse sentido, há uma unificação e desterritorialização dos bens, das pessoas e das informações que circulam universalmente pelo mundo, causando uma crise de identidade do sujeito pela abrangência de referências com as quais se depara no cotidiano. Destarte, Lipovetsky e Serroy discutem sobre a centralidade e a desorientação dessa cultura globalizada.

No primeiro capítulo, "A cultura como mundo e como mercado", os autores discutem sobre a pulverização contemporânea do quadro de referências identitárias, antes na modernidade, mais estáveis. $\bigcirc$ capítulo inicial centra a análise em torno 
de quatro polos que estruturariam o mundo hipermoderno dos novos tempos: o hipercapitalismo, a hipertecnização, o hiperindividualismo e o hiperconsumo.

Segundo os autores, o hipercapitalismo, desde 1980, se constitui como o principal fator da globalização financeira. A hipertecnização se refere à inovação e ao crescente universo técnico-científico que domina amplamente o mundo atual. $\bigcirc$ hiperindividualismo se caracteriza pelas mudanças políticas, sociais e econômicas que fizeram com que as sociedades antigas organizadas mais coletiva e holisticamente se voltassem, de modo hegemônico, ao indivíduo. $\bigcirc$ hiperconsumo está ligado à ideia de uma cultura globalizada em que há uma comercialização planetarizada.

O segundo capítulo, "O mundo como imagem e como comunicação", por meio do referencial teórico da Escola de Frankfurt de Adorno e Horkheimer, aborda especificamente sobre os limites e as possibilidades de ação da indústria cultural em uma cultura globalizada. Atualmente, o sujeito cada vez mais envolvido com as tecnologias midiáticas se torna um receptáculo de uma série de informações provindas de todos os lugares do mundo a qualquer momento.

Lipovetsky e Serroy argumentam sobre uma universalização de idolatrias concernentes a personagens/ celebridades do âmbito da televisão e do cinema que acabam se tornando referências em todo mundo. Tal fenômeno de caráter mercadológico que invade a produção cultural também se direciona às artes clássicas ou tradicionais a partir da lógica do mercado capitalista.

O terceiro capítulo, "A cultura-mundo como mitos e como desafios", traz reflexões da cultura-mundo encarnada de uma padronização de mercadorias culturais, em grande parte, ditada pela ordem mercantil norte-americana. Há produtos de aceitação mundial que tendem a homogeneizar as demandas dos consumidores. No entanto, a recepção de determinado produto propalado pelos mecanismos da indústria cultural pode ser incorporado (a)criticamente ou adaptado a depender do grupo e do espaço-tempo na qual foi absorvido.

Em termos gerais, para Lipovetsky e Serroy, o que de modo universal é imposto, localmente pode ser concebido de forma questionadora. Ademais, ao mesmo tempo em que há uma expansão de produtos mundiais, existe uma necessidade de diferenciação por parte do indivíduo. Portanto, a cultura-mundo se caracteriza por um continuum entre demandas mundiais e interesses particulares/tradicionais.

No último capítulo, "A cultura-mundo como civilização", Lipovetsky e Serroy discutem a possibilidade da sociedade atual valorizar aspectos positivos que derivariam das tensões paradoxais, híbridas, contraditórias e ambivalentes da cultura-mundo. Os autores propõem um debate acerca da formação para o mundo, a partir da combinação do que há de produtivo nos modelos pedagógicos antigos e atuais no âmbito da escola. Em seguida, os autores versam sobre a construção de 
uma cultura geral no sentido histórico de orientar a sociedade a partir de valores partilhados e de sentidos. Posteriormente, ratifica-se a capacidade das instituições universitárias em formar homens de consciência crítica face ao mundo complexo dos dias de hoje.

Em outro momento, ainda no capítulo final do livro, diante do desenvolvimento da sociedade de consumo de massa, questionam-se os esforços estatais em privilegiar certas categorias sociais, haja vista que a intervenção do Estado cada vez mais está atravessada por iniciativas privadas responsáveis por atender majoritariamente determinada elite em detrimento do interesse público/ coletivo. Por fim, pondera-se sobre a necessidade da civilização mundial de pensar em perspectivas futuras de interesses e de necessidades dos homens, bem como valorizar a diversidade dos grupos sociais - leia-se primordialmente contra o preconceito às minorias.

As conclusões do livro de Lipovetsky e Serroy para a área de Educação Física/ Ciências do Esporte podem indicar fundamentalmente que os inúmeros ideais de corpo coexistentes na hipermodernidade se configuram, em parte, como promessas inalcançáveis em que os sujeitos buscam e se espelham durante o cotidiano. Cada vez mais, o aparente "sucesso corporal" em vias de ser conquistado se deve, de maneira exclusiva, ao esforço e à vontade do sujeito. Baseando-se nas considerações de Lipovetsky e Serroy, na atual era primordialmente individualista, o homem contemporâneo se sente obrigado a (re)criar a sua identidade.

Antes, na antiga modernidade, havia regras da vida social atreladas a macrodiscursos tradicionais e doutrinários que regiam grande parte das coletividades. Atualmente, na hipermodernidade, como Lipovetsky e Serroy descrevem, há uma sociedade dita democrática em que o sujeito é "livre" nas suas escolhas. Assim, nas palavras dos autores do livro, cria-se uma "vida à la carte", em que o Homo individualis opta por um múltiplo quadro de referências identitárias em relação ao corpo, como a obsessão com a saúde, o culto a forma corporal, os cuidados de beleza, a busca pela magreza, etc.

Desse modo, como o subtítulo do livro sugere, destaca-se que exista uma "sociedade desorientada" entremeada a uma cultura hedonista e narcisista. Indubitavelmente, nesse panorama contemporâneo de inúmeras tendências de conceber o corpo, a área de Educação Física/ Ciências do Esporte se torna uma das principais frentes de contenção desse caos referente à (re)construção de identidades da vida hipermoderna.

Se alinhando ao cenário teórico delineado por Lipovetsky e Serroy de que a cultura é um setor econômico em plena expansão, é possível refletir, portanto, sobre o processo de mercadorização do corpo contemporâneo no âmbito da Educação Física/ Ciências do Esporte. A busca exacerbada de determinados estereótipos 
corporais atrelados à saúde ou à beleza são constantemente propalados como um valor identitário da vida cotidiana, fenômeno este presente no espaço de atuação e de reflexão do profissional de Educação Física.

Assim, compreender em que medida as referências de corpo nesse contexto de "capitalismo cultural", termo usado por Lipovetsky e Serroy, engendram as relações sociais e como a Educação Física/ Ciências do Esporte lida com essas demandas parece ser um tópico atual de suma importância para o debate acadêmico-profissional da área. As argumentações sobre a cultura-mundo indicam a necessidade dos profissionais da área de Educação Física/ Ciências do Esporte de se comprometerem com emancipação do público no qual intervêm, seja nas escolas, nas academias de ginástica, nos clubes, etc, no sentido de desmistificar determinadas ideologias transitórias que atravessam os modelos de corpo.

Nesta pulverização da cultura somática, as pessoas com as quais os profissionais da área de Educação Física/ Ciências do Esporte lidam no cotidiano estão, a todo o momento, envolvidas por diversos discursos de quais comportamentos devem adotar para alcançarem determinados ideais de corpo. Para Lipovetsky e Serroy, este instável e amplo leque de opções dado ao sujeito acarreta em uma relativa desestabilização da visão de mundo dos grupos sociais. Nesse sentido, a área de Educação Física/ Ciências do Esporte pode contribuir para mediar os atuais lugares sociais dos sujeitos da hipermodernidade, pois as identidades se tornam cada vez mais complexas na medida em que se evidenciam como abertas, temporárias, dinâmicas, negociáveis e indeterminadas.

Os valores dados a determinados atributos corporais como, por exemplo, os padrões de uma bela aparência e as supostas condições ideais de saúde, levam o sujeito a ficar "desnorteado e frágil" diante de si. Para os autores do livro, o processo da atual ordem social contribui para as identidades entrarem em crise, uma vez que o mesmo sujeito aciona diversos dispositivos para dar sentido a sua vida - leia-se corporal. Destarte, face a este contexto de (re)produções de lógicas culturais da vida cotidiana, os profissionais de Educação Física/ Ciências do Esporte se tornam importantes para os sujeitos ressignificarem os diversos discursos que circulam em relação ao corpo.

Muitas vezes, o atual campo das práticas corporais está envolvido por uma cultura comercial de múltiplos macrodiscursos que incitam uma negociação de compra e venda de uma suposta condição de ser saudável e/ou belo. Para além de estar tecnicamente capacitado, de modo crítico-reflexivo no sentido de compreender os aspectos culturais não ligados somente a referências totalizantes e universais, o profissional de Educação Física imerso nessa cultura-mundo pode pensar e envolver os sujeitos de determinados contextos socioculturais em direção a um processo dialógico de ampliação de diferentes formas de ser (corporal) no mundo. 
A partir de uma linguagem instigante e de reflexões críticas sobre a sociedade atual, indubitavelmente, Lipovetsky e Serroy proporcionam uma leitura indispensável para aqueles que se debruçam em discussões socioculturais acerca do corpo na contemporaneidade no nível da produção científica e da intervenção profissional na área de Educação Física/ Ciências do Esporte.

\section{REFERÊNCIAS}

LIPOVETSKY, G. O império do efêmero: a moda e seu destino nas sociedades modernas. Trad. Maria L. Machado. São Paulo: Companhia das Letras, 2009.

Recebido em: 14 abr. 2013 Aprovado em: 9 jun. 2013

Alan Camargo Silva Av. Marechal Henrique Lott, n. $70 /$ apt. 1014 Barra da Tijuca Rio de Janeiro-RJ CEP: 2263।-370 